\section{Intraspecific genetic variation within and between improved cultivars and landraces of durum wheat in germination and root architectural traits under saline conditions}

\author{
Nidal Odat \\ Department of Biotechnology, Al Balqa \\ Applied University, Al Salt, Jordan
}

\begin{abstract}
Although the effect of salinity on plants is well established, yet evaluating genetic variation in yield-related traits under salinity stress remains useful. This study was conducted to investigate the genetic variation within and between two subgroups of durum wheat in Jordan, i.e., cultivars and landraces, in germination and root architectural traits at three salinity concentrations (50, 100 and $150 \mathrm{mM} \mathrm{NaCl})$. The results indicate that salinity significantly impacted most traits investigated. A multivariate discriminant analysis (DA) revealed large variations ( $~ 85 \%)$ between genotypes, with significant ranking in maximum root length, total root length, seminal root length, coleoptile length, germination percentage, and total and seminal root number over the three salinities. Within the cultivar subgroup, salinity significantly influenced the germination percentage and most root traits of durum genotypes, with variable magnitudes depending on $\mathrm{NaCl}$ concentration and within-variety intraspecific genetic variation (ANOVAs; $\mathrm{P}<0.05$ ). However, within the landrace subgroup, only a salinity of $150 \mathrm{mM} \mathrm{NaCl}$ significantly affected the studied traits, and the effect of salinity on germination percentage was highly genotype dependent. Additionally, the durum genotypes in the landrace subgroup were more affected by salinity and showed more genetic variation than those in the cultivar subgroup.
\end{abstract}

\section{Introduction}

Durum wheat (Triticum turgidum L. spp. durum Desf.) is a tetraploid grass with nutritional value for humans. This crop was originally domesticated in the Fertile Crescent and then spread, over several generations, to diverse areas worldwide, where it has been subjected to natural and artificial selection processes. Domestication and later breeding have resulted in the develop- ment of varied local landraces and modern cultivars. Intraspecific genetic variation in crop plants is believed to affect many phenotypic traits related to growth and development. ${ }^{1}$ Therefore, understanding the genetic variation underlying the varied phenotypes of a crop under environmental stress is important.

Durum wheat is grown in Jordan as it is a major constituent of various traditional dishes including Kibbeh, Bulgur, Maftoul, and Tabbouleh. However, growers of durum wheat in Jordan, as in many arid and semiarid regions worldwide, suffer from reduced productivity in most cereal crops due to the prevalence of soil salinity. ${ }^{2}$ Soil salinity limits crop productivity by influencing key growth and developmental processes, such as the germination process; by damaging living cells through ionic toxicity, chiefly sodium $\left(\mathrm{Na}^{+}\right)$and chloride $\left(\mathrm{Cl}^{-}\right)$; and by reducing water availability due to osmotic effects. ${ }^{3,4}$

Seed germination is an important determinant of the successful establishment of a crop and can be greatly inhibited by stress factors that delay germination or retard seed viability. ${ }^{5-7}$ In addition to germination, salinity may affect other yield-related traits of crops, including the architectural traits of the root system, such as total root length, number of seminal roots, and coleoptile length. ${ }^{8-10}$ Germination and root traits are believed to play an important role in shaping the tolerance of a crop to a stressful environment and thus can be utilized as suitable traits for selection in crop improvement. ${ }^{11,12}$

Although the response of plants to $\mathrm{NaCl}$ stress is known, evaluating intraspecific genetic variation in yield-related traits in response to stress factors remains important, as it can be useful in screening for genotypes with improved tolerance to saline fields. ${ }^{13,14}$ However, selecting salt-tolerant genotypes by evaluating genotypic variation in the field has been proven to be rather misleading: first, because the salinity effect is difficult to disentangle from the many other effects of the biotic and abiotic factors encountered, and second, because of the required labor and resources, i.e., time and consumables, especially in long-term experiments with a large number of genotypes. ${ }^{15}$ Alternatively, short-term greenhouse experiments of a few days to a week in duration have been favored to identify salt-tolerant genotypes by comparing differential responses in controlled saline and nonsaline conditions.

In this study, the intraspecific genetic variation in 13 yield-related traits of two groups ( 3 cultivar genotypes and 3 landrace genotypes) of durum wheat that are mainly
Correspondence: Nidal Odat, Department of Biotechnology, Faculty of Agricultural Technology, Al Balqa Applied University, 19117 Al Salt, Jordan.

Tel.: +962.5.3532519 - Fax: +962.5.3530469.

E-mail: nidalodat@gmail.com

Key words: Durum wheat, germination, root traits, intraspecific variation, salinity stress.

Funding: This work was financed by the Deanship of Scientific Research of Al Balqa Applied University. The author acknowledges NCARE of Jordan for providing the seeds and Ms. Aya Awad for laboratory assistance.

Conflict of interest: the author declares no potential conflict of interest.

Received for publication: 18 September 2017. Accepted for publication: 25 October 2017.

This work is licensed under a Creative Commons Attribution-NonCommercial 4.0 International License (CC BY-NC 4.0).

${ }^{C}$ Copyright: the Author(s), 2020

Licensee PAGEPress srl, Italy

International Journal of Plant Biology 2020; $11: 7413$ doi:10.4081/pb.2020.7413

grown in Jordan is evaluated to advise local durum wheat growers of possible salt-tolerant genotypes and to better understand the genetic influences underlying these yieldrelated traits in saline conditions.

\section{Materials and Methods \\ Plant material and growth condi- tions}

The seeds of the studied genotypes of durum wheat were obtained from the National Center for Agricultural Research and Extension (NCARE) of Jordan. These genotypes were of two groups: cultivars (Deir alla 6, Acsad 65, and Sham 1) and local landraces (Um-qais, Hourani 27, and Noorseh). The genotypes were varied in their countries of origin and pedigrees (Table 1). Initially, the seeds were treated with $1 \%(\mathrm{w} / \mathrm{v})$ sodium hypochlorite solution for sterilization, and then thoroughly washed with distilled water. The sterilized seeds were then placed into Petri dishes (100 $\mathrm{mm}$ in diameter) containing two pieces of filter paper and then moistened with distilled water or with one of the $\mathrm{NaCl}$ solutions $(50,100$ and $200 \mathrm{mM})$ with electrical conductivities of $4.2 \mathrm{dS} \mathrm{m}^{-1}, 8.3 \mathrm{dS} \mathrm{m}^{-1}$ and $12.1 \mathrm{dS} \mathrm{m}^{-1}$, respectively. The dishes of treated seeds were sealed with Parafilm and arranged randomly in a growth chamber at 
$25^{\circ} \mathrm{C}$. Germination was evaluated daily and was judged to occur if a radicle length of approximately $2 \mathrm{~mm}$ was observed. Germination percentage (G\%) was calculated as follows: $\mathrm{G} \%=100(\mathrm{GS} / \mathrm{TS})$, where $\mathrm{GS}=$ germinated seeds and TS $=$ total seeds incubated. To measure changes in root traits, digital photographs of the root architecture were taken for total root length, maximum root length, seminal root length, and coleoptile length, and the images were converted to high-contrast black-and-white pictures using Adobe Photoshop software. These images were then used to measure the root lengths with the help of ImageJ (https://imagej.nih.gov/ij/). Seminal root numbers of the studied genotypes were counted for 10 randomly sampled germinated seeds. For the estimation of chlorophyll content, approximately $0.2 \mathrm{~g}$ of the youngest leaf tissues was ground in $10 \mathrm{ml}$ of $80 \%$ acetone with a mortar and pestle, and then the extract was transferred into Falcon tubes and centrifuged for 15 minutes at $15,000 \mathrm{rpm}$. The supernatant of the centrifuged solution was then transferred into new tubes and kept on ice. The absorbance of the supernatant was measured at $\mathrm{OD}_{645}$ and $\mathrm{OD}_{663} \mathrm{~nm}$ using a Spectrophotometer (Biochrom Ltd, Cambridge, UK). The measured absorbance were then used as inputs to estimate the concentrations of total chlorophyll, chlorophyll a, and chlorophyll b. ${ }^{16}$ Stomatal conductance was measured using a Delta-T AP4 cycling diffusion porometer (Delta-T Devices Ltd, Burwell, UK) using the uppermost fully expanded leaves.

\section{Data analysis}

Data analysis for germination and morphological traits was based on the means of four replicates. The measured traits were first subjected to modeling with a multivariate discriminant analysis (DA) to identify the traits most affected by salinity and to summarize the resulting responses to salinity treatments. In the DA model, salinity concentrations of 50, 100 and $150 \mathrm{mM}$ $\mathrm{NaCl}$ were used as predefined groups, and the trait estimates were entered into the model simultaneously in a standard procedure. The ranking of the studied traits according to their relative importance by genotype was based upon $\mathrm{F}$ and $P$ values. Moreover, the effect of each salinity level on the studied traits was tested with a oneway analysis of variance (ANOVA), and two- and three-way ANOVAs were used to examine the possible interaction effects of salinity according to within- and betweengroup intraspecific variation. Data were analyzed using IBM SPSS (SPSS Inc., Chicago, USA).
Table 1. Name, origin and pedigree of studied wheat genotypes.

\begin{tabular}{lll}
$\begin{array}{l}\text { Genotype } \\
\text { identification } \\
\text { name }\end{array}$ & Country of origin & Pedigree \\
Um-qais & Jordan & Landrace \\
Noorseh & Jordan & Landrace \\
\hline Hourani 27 & Jordan & Landrace \\
Deir alla 6 & Jordan & YEMEN X Cr's'X PLc's'/'Gto's CM 18687-D85-D11 \\
\hline Acsad 65 & ICARDA/Syria & GERARDO-VZ-469/3/JORI-1/ND-61-130/LEEDS \\
Sham 1 & ICARDA/Syria & PELICANO/RUFF//GAVIOTA/ROLETTE; \\
& & PELICANO(SIB)/(SIB)RUFF//GAVIOTA \\
& & SIB)/(SIB)ROLETTE \\
\hline
\end{tabular}

*ICARDA, International Center for Agricultural Research in the Dry Areas.



Salinity $(\mathrm{NaCl} \mathrm{mM})$

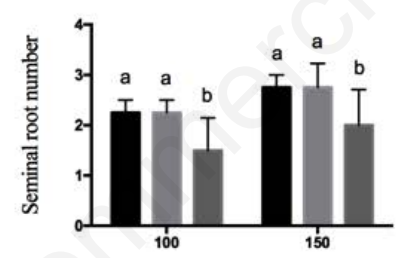

Salinity $(\mathrm{NaCl} \mathrm{mM})$

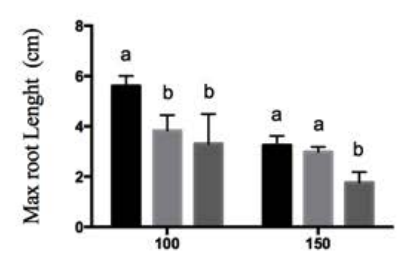

Salinity $(\mathrm{NaCl} \mathrm{mM})$



Salinity $(\mathrm{NaCl} \mathrm{mM})$

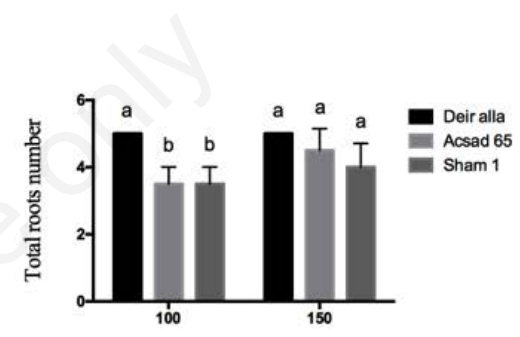

Salinity $(\mathrm{NaCl} \mathrm{mM})$



Salinity $(\mathrm{NaCl} \mathrm{mM})$

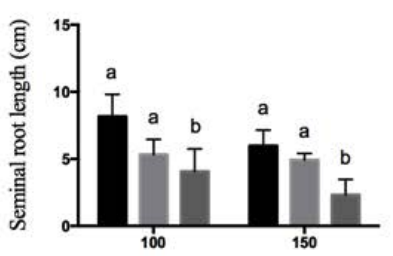

Salinity $(\mathrm{NaCl} \mathrm{mM})$
Figure 1. Genotypic variation in germination percentage and root architectural traits in three cultivars of durum wheat at salinities of 100 and $150 \mathrm{mM} \mathrm{NaCl}$. Bars represent the means \pm standard error of four individuals per genotype. Different letters indicate significant differences between genotypes at $\mathrm{P} \leq 0.05$. 


\section{Results and Discussion}

The results of this study illustrate that, depending on $\mathrm{NaCl}$ concentration and on the intraspecific genetic variation of the studied genotypes, salinity negatively affects the germination and root traits of durum wheat. A multivariate DA of all studied traits resulted in two functions with a combined prediction of salinity effect of approximately $60 \%$ across the three salinity concentrations, i.e., 50, 100, and $150 \mathrm{mM}$ $\mathrm{NaCl}$ (Table 2). In particular, the prediction of the DA model was $84 \%$ for the $150 \mathrm{mM}$ $\mathrm{NaCl}$ concentration and $54 \%$ and $42 \%$ for the 50 and $100 \mathrm{mM} \mathrm{NaCl}$ concentrations, respectively, implying that genotypic differences in germination and root architectural traits are best assessed at the highest level of salinity, i.e., $150 \mathrm{mM} \mathrm{NaCl} .{ }^{17}$ To determine the ranking of the traits that best discriminated the durum genotypes, two DA canonical axes were obtained; the first explained a total variation of approximately $85 \%$ with significant loadings for maximum root length, total root length, seminal root length, coleoptile length, germination percentage, and total and seminal root numbers (Table 2). In DA, a greater magnitude of the discriminant function coefficient (regardless of sign) indicates a greater contribution of that trait to the total observed variation. The results of the DA indicate that the studied traits are suitable metrics for elucidating salinity effects in durum wheat, as they show significant total variation among wheat genotypes, and this variation may suggest their importance in screening for salt-tolerant and salt-sensitive genotypes. ${ }^{14}$

Furthermore, to see if these traits were similarly affected by different salinity concentrations, one-way ANOVAs were conducted. According to this analysis, a salinity of $150 \mathrm{mM} \mathrm{NaCl}$, relative to control $(0 \mathrm{mM}$ $\mathrm{NaCl}$ ), significantly decreased the total, maximum, and seminal axile root lengths and the coleoptile length in the Deir alla 6 genotype, while salinities of 50 and 100 $\mathrm{mM} \mathrm{NaCl}$ did not affect any of the traits studied (Table 3). For the genotype Sham 1, a salinity of $150 \mathrm{mM} \mathrm{NaCl}$ also resulted in a decrease in germination percentage and a reduction in total and maximum root lengths, while a salinity of $100 \mathrm{mM} \mathrm{NaCl}$ reduced total root number and maximum root length. The Acsad 65 genotype was found to be the least affected, as only the coleoptile length was reduced and only by a salinity of $150 \mathrm{mM} \mathrm{NaCl}$ (Table 3). The effects of salinity on germination percentage and root traits are best attributed to the reduced water availability caused by osmotic stress rather than to ionic stress. ${ }^{2,9}$ Additionally, these results reveal differen-
Table 2. Canonical variable loadings, percentage of variation, and canonical correlation results of a DA of the germination and root architectural traits for all genotypes of durum wheat subjected to different salinities. Unstandardized coefficients from the discriminant functions and predicted classifications are presented: a $100 \%$ prediction means that, with the variables used, a $100 \%$ discrimination of the three salinities can be obtained.

\begin{tabular}{lll} 
Traits & Canonical variable 1 & Canonical variable 2 \\
Germination & 0.192 & -0.247 \\
Number of roots & -0.407 & 0.602 \\
\hline Root length & -0.700 & -0.138 \\
Coleoptile length & -0.146 & 0.376 \\
\hline Number of seminal roots & 0.189 & 0.524 \\
Seminal root length & -0.487 & -0.720 \\
\hline Maximum root length & 2.148 & 0.189 \\
Percentage of variance & 84.60 & 15.4 \\
\hline Canonical correlation & 0.520 & 0.252 \\
Predicted classification & & \\
$50 \mathrm{mM} \mathrm{NaCl}$ & $54.2 \%$ & \\
$100 \mathrm{mM} \mathrm{NaCl}$ & $41.7 \%$ & \\
$150 \mathrm{mM} \mathrm{NaCl}$ & $83.3 \%$ & \\
\hline
\end{tabular}
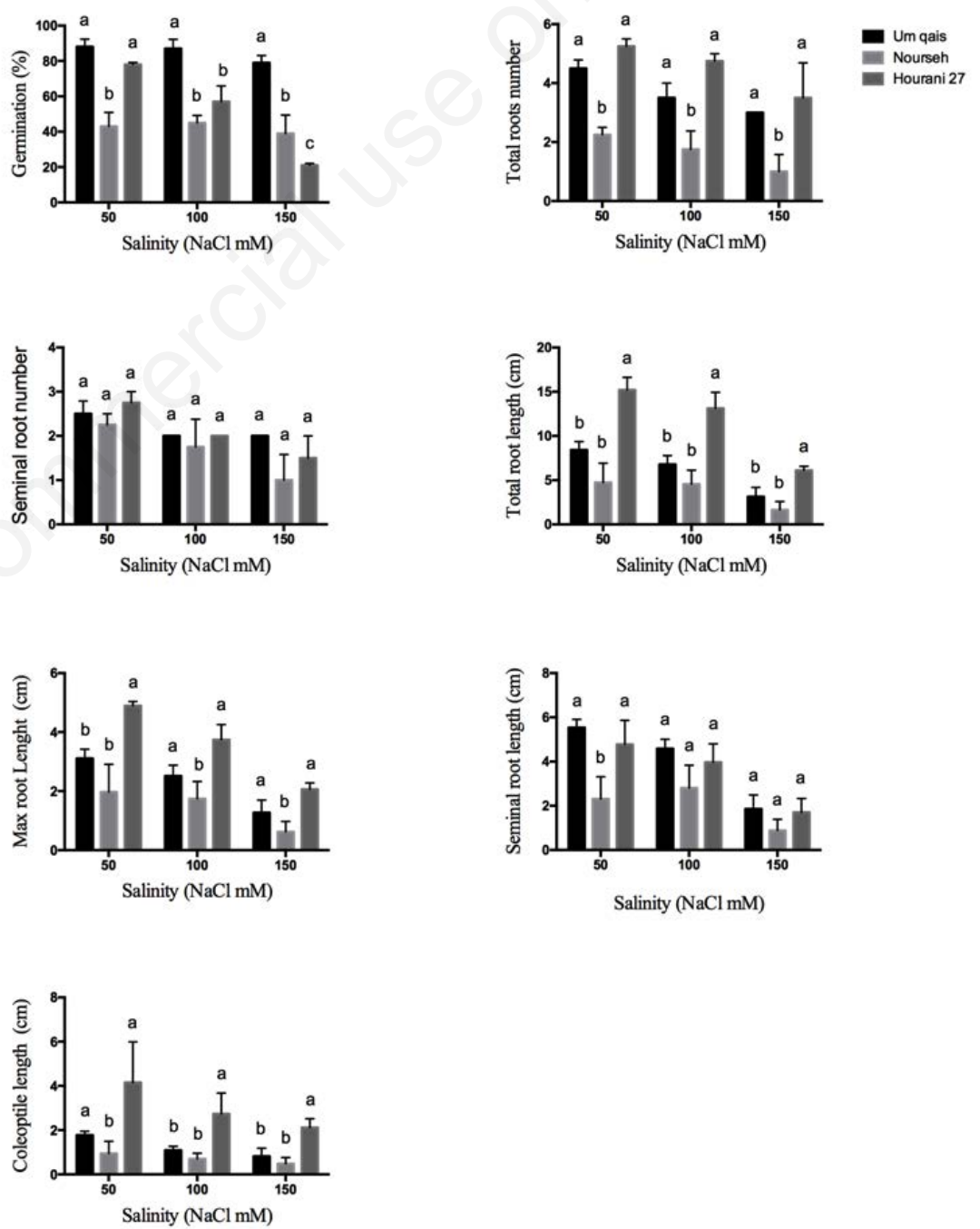

Figure 3. Variation between the landrace and cultivar subgroups of durum wheat in germination percentage and root architectural traits when grown on media containing 50 $\mathrm{mM}, 100 \mathrm{mM}$ and $150 \mathrm{mM} \mathrm{NaCl}$. Points represent the means \pm standard error of four individuals per genotype. Asterisks $\left(^{*}\right)$ indicate significant differences at $\mathrm{P} \leq 0.05$; $\left({ }^{* *}\right)$ at $<0.01$; and $\left(^{* * *}\right)$ at $<0.001$. 
tial responses between genotypes in the cultivar subgroup in germination and most root architectural traits. Namely, the germination percentage, the root traits and coleoptile length were profoundly affected especially in sham 1 followed by Acsad 65 and lessely in Dear allah (Figure 1). Accordingly, the genotypes can be ranked by the number of traits indicating tolerance as salt-tolerant $>$ salt-sensitive as follows: Deir alla $6>$ Acsad $65>$ Sham 1. Therefore, Deir alla 6 seems to be a salt-tolerant genotype, and Sham 1 seems to be a salt-sensitive genotype. These results suggest the suitability of these traits for classifying the studied genotypes into salt-tolerant and salt-sensitive genotypes. ${ }^{15}$

To discover whether the genetic variation of genotypes in the cultivar subgroup interactively underlies variation in germination and root traits, two-way ANOVAs for the effects of salinity, genotype, and their interaction were performed (Table 4). The analysis showed that total, seminal, and maximum root lengths and coleoptile length were all associated with intraspecific genetic variation and that the combined effect of genotype and salinity was not significant for any trait (two-way ANOVA; P>0.05).

However, in the landrace subgroup, a one-way ANOVA showed that a salinity of $150 \mathrm{mM} \mathrm{NaCl}$ differentially affected all traits studied except for total root number (Table 3). Specifically, the germination percentage and total and maximum root lengths were significantly affected in both Um-qais and Hourani 27, while the number of seminal roots, length of seminal root and coleoptile length were also affected in Umqais. Based on their differential responses to salinity, the genotypes in the landrace subgroup can be ranked as salt-tolerant $>$ saltsensitive as follows: Um-qais $>$ Hourani 27 $>$ Noorseh (Figure 2).

Unlike the genotypes in the cultivar subgroup, all studied traits in the landrace subgroup were found to be associated with genetic variation, and the effect of salinity on germination percentage was highly genotype-dependent, as a significant salinity $\mathrm{x}$ genotype interaction was found (Table 5). Additionally, durum genotypes in the landrace subgroup were found to be more affected by salinity and showed a larger genetic variation than cultivar genotypes, especially in germination and root traits (Figure 3). This larger genetic variation in landraces compared with improved varieties could be attributed to the fact that landraces are typically more adapted to varied stressful environments. ${ }^{18}$
Table 3. Mean estimates, based on four independent replicates, of germination percentage and root architectural traits of the studied durum wheat varieties (cultivars and landraces) under three salinity concentrations $(50,100$, and $150 \mathrm{mM} \mathrm{NaCl})$ and their variations relative to the control $(0 \mathrm{mM} \mathrm{NaCl})$ as measured using a one-way ANOVA.

\begin{tabular}{|c|c|c|c|c|}
\hline \multirow[t]{2}{*}{ Variety type } & \multirow[t]{2}{*}{ Dependent variable } & \multicolumn{3}{|c|}{ Salinity (mM) } \\
\hline & & 50 & 100 & 150 \\
\hline \multicolumn{5}{|l|}{ Cultivars } \\
\hline Deir alla 6 & $\begin{array}{l}\text { Germination percentage } \\
\text { Number of roots } \\
\text { Number of seminal roots } \\
\text { Total root length } \\
\text { Seminal root length } \\
\text { Maximum root length } \\
\text { Coleoptile length }\end{array}$ & $\begin{array}{c}73.00 \\
4.50 \\
2.00 \\
17.96 \\
7.08 \\
5.19 \\
3.04\end{array}$ & $\begin{array}{c}85.00 \\
5.00 \\
2.25 \\
18.77 \\
8.16 \\
5.61 \\
3.27\end{array}$ & $\begin{array}{c}85.00 \\
5.00 \\
2.75 \\
11.20^{*} \\
5.97^{*} \\
3.25^{*} \\
2.28^{*}\end{array}$ \\
\hline Acsad 65 & $\begin{array}{l}\text { Germination percentage } \\
\text { Number of roots } \\
\text { Number of seminal roots } \\
\text { Total root length } \\
\text { Seminal root length } \\
\text { Maximum root length } \\
\text { Coleoptile length }\end{array}$ & $\begin{array}{c}76.00 \\
4.50 \\
2.50 \\
13.55 \\
7.09 \\
4.89 \\
3.47\end{array}$ & $\begin{array}{l}77.00 \\
3.50 \\
2.25 \\
9.96 \\
5.32 \\
3.82 \\
3.05\end{array}$ & $\begin{array}{c}81.00 \\
4.50 \\
2.75 \\
9.47 \\
4.92 \\
2.98 \\
2.10^{* *}\end{array}$ \\
\hline Sham 1 & $\begin{array}{l}\text { Germination percentage } \\
\text { Number of roots } \\
\text { Number of seminal roots } \\
\text { Total root length } \\
\text { Seminal root length } \\
\text { Maximum root length } \\
\text { Coleoptile length }\end{array}$ & $\begin{array}{c}90.00 \\
4.25 \\
2.00 \\
11.99 \\
3.91 \\
3.58 \\
2.31\end{array}$ & $\begin{array}{c}85.00 \\
3.50^{*} \\
1.50 \\
9.67 \\
4.07 \\
3.30^{*} \\
1.65\end{array}$ & $\begin{array}{c}56.01^{*} \\
4.00 \\
2.00 \\
4.94^{*} \\
2.32 \\
1.76^{* *} \\
1.28\end{array}$ \\
\hline \multicolumn{5}{|l|}{ Landraces } \\
\hline Um-qais & $\begin{array}{l}\text { Germination percentage } \\
\text { Number of roots } \\
\text { Number of seminal roots } \\
\text { Total root length } \\
\text { Seminal root length } \\
\text { Maximum root length } \\
\text { Coleoptile length }\end{array}$ & $\begin{array}{c}88.00 \\
4.5 \\
2.50 \\
8.41 \\
5.53 \\
3.11 \\
1.78\end{array}$ & $\begin{array}{c}87.00 \\
3.50 \\
2.00 * \\
6.77 \\
4.58 \\
2.51 \\
1.09\end{array}$ & $\begin{array}{c}79.00^{*} \\
3.00 \\
2.00^{*} \\
3.12^{* *} \\
1.85^{* *} \\
1.27^{* *} \\
0.82^{*}\end{array}$ \\
\hline Noorseh & $\begin{array}{l}\text { Germination percentage } \\
\text { Number of roots } \\
\text { Number of seminal roots } \\
\text { Total root length } \\
\text { Seminal root length } \\
\text { Maximum root length } \\
\text { Coleoptile length }\end{array}$ & $\begin{array}{l}43.00 \\
4.00 \\
2.25 \\
4.74 \\
2.31 \\
1.97 \\
0.95\end{array}$ & $\begin{array}{l}45.00 \\
2.50 \\
1.75 \\
4.55 \\
2.80 \\
1.74 \\
0.70\end{array}$ & $\begin{array}{l}39.00 \\
2.00 \\
1.00 \\
1.63 \\
0.88 \\
0.62 \\
0.48\end{array}$ \\
\hline Hourani 27 & $\begin{array}{l}\text { Germination percentage } \\
\text { Number of roots } \\
\text { Number of seminal roots } \\
\text { Total root length } \\
\text { Seminal root length } \\
\text { Maximum root length } \\
\text { Coleoptile length }\end{array}$ & $\begin{array}{c}78.00 \\
5.25 \\
2.75 \\
15.19 \\
4.77 \\
4.89 \\
4.15 \\
\end{array}$ & $\begin{array}{c}57.00 \\
4.75 \\
2.00 \\
13.12 \\
3.97 \\
3.74 \\
2.74 \\
\end{array}$ & $\begin{array}{l}21.00^{* *} \\
3.50 \\
1.50 \\
6.11^{* *} \\
1.70 \\
2.06^{*} \\
2.12 \\
\end{array}$ \\
\hline
\end{tabular}

*Significant at $\mathrm{P} \leq 0.05$; ** significant at $\mathrm{P}<0.01$.

Table 4. Summary of the P values of two-way ANOVAs for the effects of salinity (S), genotype $(G)$, and their interaction $(S+G)$ on the germination and root architectural traits of durum wheat cultivars.

\begin{tabular}{lccc}
\hline Traits / source of variation & S & G & S + G \\
Germination percentage & 0.45 & 0.83 & 0.064 \\
Number of roots & 0.44 & 0.09 & 0.61 \\
\hline Number of seminal roots & 0.35 & 0.15 & 0.90 \\
Root length & 0.04 & 0.01 & 0.78 \\
\hline Seminal root length & 0.27 & 0.008 & 0.87 \\
Maximum root length & 0.009 & 0.020 & 0.842 \\
\hline Coleoptile length & 0.017 & 0.004 & 0.827 \\
\hline
\end{tabular}




\section{Conclusions}

Because germination and root traits in wheat are positively related to increased grain number and productivity in the field, the results of this study maybe suggest their suitability as target phenotypes for genetic improvement to increase wheat productivity

Table 5. Summary of the P values of two-way ANOVAs for the effects of salinity (S), genotype $(G)$, and their interaction $(S+G)$ on the germination and root architectural traits of durum wheat landraces.

\begin{tabular}{lccc} 
Traits / source of variation & S & G & S + G \\
Germination percentage & 0.000 & 0.000 & 0.002 \\
Number of roots & 0.018 & 0.026 & 0.953 \\
\hline Number of seminal roots & 0.008 & 0.214 & 0.773 \\
Root length & 0.000 & 0.000 & 0.283 \\
\hline Seminal root length & 0.000 & 0.010 & 0.660 \\
Maximum root length & 0.000 & 0.000 & 0.651 \\
\hline Coleoptile length & 0.179 & 0.002 & 0.872 \\
\hline
\end{tabular}
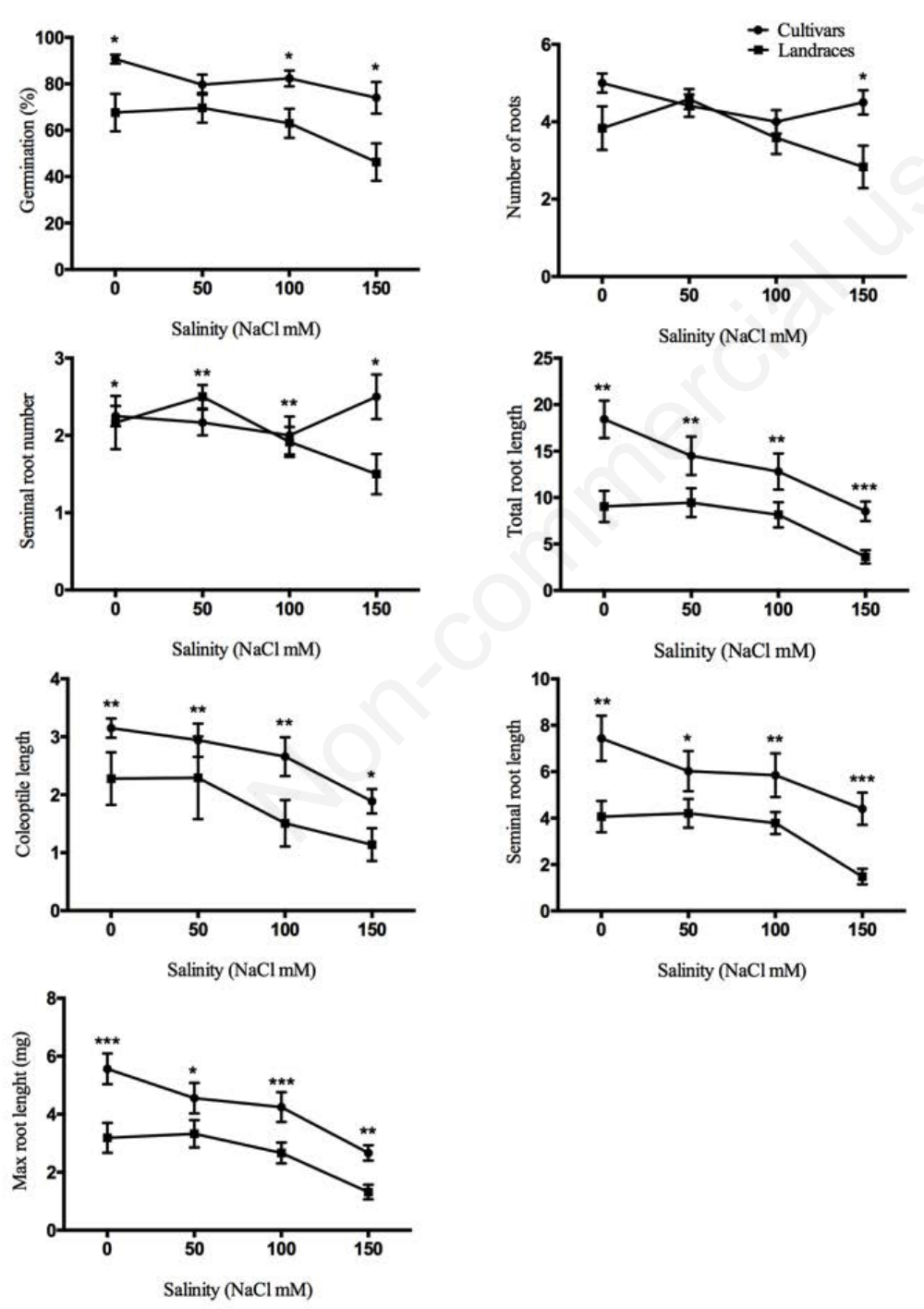

Figure 2. Genotypic variation in germination percentage and root architectural traits in three landraces of durum wheat at salinities of 100 and $150 \mathrm{mM} \mathrm{NaCl}$. Bars represent the means \pm standard error of four individuals per genotype. Different letters indicate significant differences between genotypes at $\mathrm{P} \leq 0.05$.

under saline soil conditions. Further research should investigate the genetic components, i.e. identify or clone the genes controlling the salt response of the salt-tolerant genotype and the salt-sensitive genotype of wheat. ${ }^{19}$

\section{References}

1. Mickelbart MV, Hasegawa PM, BaileySerres J. Genetic mechanisms of abiotic stress tolerance that translate to crop yield stability. Nat Rev Genet 2015; 16:237-51.

2. Acosta-Motos J, Ortuño M, BernalVicente A, et al. Plant responses to salt stress: adaptive mechanisms. Agronomy 2017;7:18.

3. Koubouris GC, Tzortzakis N, Kourgialas NN, et al. Growth, photosynthesis and pollen performance in saline water treated olive plants under high temperature. Int $\mathrm{J}$ Plant Biol 2015;6:28-32

4. Çavuşoğlu K, Kiliç S, Kabar K. Some morphological and anatomical observations during alleviation of salinity $(\mathrm{NaCl})$ stress on seed germination and seedling growth of barley by polyamines. Acta Physiol Plant 2007;29: 551-7.

5. Willis CG, Baskin C, Baskin J, et al. Dormancy and diversification: environmentally cued dormancy, evolutionary hubs, and diversification of the seed plants. New Phytol 2014;203:300-9.

6. Shu K, Meng YJ, Shuai HW, et al. Dormancy and germination: How does the crop seed decide? Plant Biol 2015;17:1104-12.

7. Öztürk A, Taşkesenlİgİl B, Halİloğlu K, et al. Evaluation of bread wheat genotypes for early drought resistance via germination under osmotic stress, cell membrane damage, and paraquat tolerance. Turk J Agric For 2016;159:14659.

8. Rebetzke GJ, Richards RA, Sirault XRR, Morrison AD. Genetic analysis of coleoptile length and diameter in wheat. Aust J Agric Res 2004;55:733-43.

9. Fogle VW, Munns DN. Effect of salinity on the time course of wheat seedling growth. Plant Physiol 1973;51:987.

10. Talbi Zribi O, Abdelly C, Debez A. Interactive effects of salinity and phosphorus availability on growth, water relations, nutritional status and photosynthetic activity of barley (Hordeum vulgare L.). Plant Biol 2011;13:872-80.

11. Ashraf M, Harris PJC. Potential biochemical indicators of salinity tolerance in plants. Plant Sci 2004;166:3-16. 
12. Munns R, Tester M. Mechanisms of salinity tolerance. Annu Rev Plant Biol 2008;59:651-81.

13. Cuin TA, Zhou M, Parsons D, Shabala S. Genetic behaviour of physiological traits conferring cytosolic $\mathrm{K}+/ \mathrm{Na}+$ homeostasis in wheat. Plant Biol 2012;14:438-46.

14. Rahnama A, Munns R, Poustini K, Watt M. A screening method to identify genetic variation in root growth response to a salinity gradient. J Exp
Bot 2011;62:69-77.

15. Munns R, James RA. Screening methods for salinity tolerance: a case study with tetraploid wheat. Plant Soil 2003;253:201-18.

16. Warren CR. Rapid measurement of chlorophylls with a microplate reader. J Plant Nutr 2008;31:1321-32.

17. James RA, Von Caemmerer S, Condon GT, et al. Genetic variation in tolerance to the osmotic stress component of salinity stress in durum wheat. Funct
Plant Biol 2008;35:111-23.

18. Luzie U, Wingen LU, West C, et al. Wheat landrace genome diversity. Genetics 2017;205:1657-76.

19. Calestani C, Moses MS, Maestri E, et al. Constitutive expression of the barley dehydrin gene aba2 enhances Arabidopsis germination in response to salt stress. Int J Plant Biol 2015;6: 2027 